\title{
EL ENCLAVE DE LA EDUCACIÓN DESDE EL ENFOQUE DE LA HERMENÉUTICA CRÍTICA ${ }^{1}$
}

\author{
JAVIER GRACIA CALADÍN E ISABEL TAMARIT \\ Universitat de València; IES Massamagrell
}

\begin{abstract}
RESUMEN: En este trabajo adoptamos una postura crítica, en primer lugar, ante un planteamiento que desde la investigación empírica pretende explicar los fines propios de la educación. Frente a éste proponemos la metodología hermenéutico-crítica para desentrañar cuáles son los fines últimos de la educación. Descubrimos que desde la metodología hermenéutico-crítica es posible enfocar adecuadamente el fin de la educación así como aportar una justificación ética solvente. Profundizando en la dimensión crítica de la hermenéutica, pero sin desvincularla de su quicio experiencial, reparamos en que no basta con interpretar los valores establecidos por la sociedad, sino que es necesario ahondar en el radical ético que justifica la educación como auténtico desarrollo humano de las capacidades morales. Esta experiencia primordial de la educación que hunde sus raíces en el radical humano es una experiencia genuinamente ética. A este respecto, destacamos once claves del enfoque éticohermenéutico y sus ventajas para la determinación del enclave de la educación.
\end{abstract}

PALABRAS CLAVE: Educación; Filosofía de la educación; hermenéutica y ética.

\section{The enclave of education \\ from the approach of critical hermeneutics.}

ABSTRACT: In this paper we adopt a critical stance, firstly, related to a view which seeks to explain the aims of education from the empirical research. Against this, we propose the hermeneutic-critical methodology to unravel what the ultimate goals of education are. We find that the approach of critical hermeneutics illuminates adequately education and provides a solvent ethical justification. Deeping on the critical dimension of hermeneutics, but without moving away from his experiential nerves, we notice that it is not enough to interpret the values set by society. It is necessary to delve into the ethical roots, which justify education as authentic human development of moral capabilities. This overriding experience of education, which is rooted in the human being, is a genuinely ethical experience. Regarding this, we emphasize eleven keys of the ethical hermeneutics and its advantages for the concretion of the enclave of the education.

KEY WORDS: Education; Philosophy of Education; Hermeneutics, and Ethics.

\section{INTRODUCCIÓN}

Muchas han sido las definiciones y los sentidos que ha recibido el término «educación» atendiendo al origen etimológico, a sus características principales, a los ámbitos y modalidades de realización del fenómeno educativo o en contraposición a otros procesos como el condicionamiento, el adoctrinamiento y el adiestramiento (cf. García Amilburu y García Gutiérrez, 2012, 47-64).

1 Este trabajo se inscribe en los proyecto de investigación «Retos Filosóficos de la educación actual» (UV-INV-PRECOMP14-205449) y en el Proyecto de Investigación Científica y Desarrollo Tecnológico «Neuroeducación moral, democracia deliberativa y políticas de desarrollo humano sostenible» FFI2016-76753-C2-1-P. 
A nuestro modo de ver, se pueden distinguir dos esferas atendiendo a elementos descriptivos y a aspectos de carácter normativo o valorativo. Aunque cada uno de los elementos puede (y debe) contribuir a una definición completa de la educación, desde planteamientos filosóficos resulta urgente atender a aquellos elementos normativos que nos permiten perfilar los rasgos más singulares de la educación (humana) y que proporcionan una comprensión mejor y más profunda de ésta.

\section{Sentido normativo o Valorativo de la educación}

Tal y como argumenta Richard Pring $(2014,256-259)$ es necesario distinguir entre un sentido descriptivo de educación y otro sentido valorativo o normativo con vistas a poder desvelar algunos «sinsentidos disfrazados» que se ocultan tras el concepto de educación, que llegan a reducir al educador a un mero gestor de la administración que ha de hacer cumplir (más o menos irreflexivamente) el currículo. Frente al sentido descriptivo referido a esas actividades e instituciones cuyo objetivo se reduce a lograr el aprendizaje aduciendo que uno estudió en determinada escuela o universidad, el sentido valorativo incide en qué consiste ser una persona educada (o maleducada). De lo que se trata no es de explicar si uno estudió en un centro o en otro, sino si la educación mereció la pena y el educando resultó una mejor persona. La educación en este sentido valorativo o normativo considera la formación del carácter y la conducta y recala en el corazón mismo de la «educación» pues no se limita a encontrar los mejores medios para que el sistema educativo sea económicamente rentable o consiga buenos profesionales sino que incide directamente en los fines mismos de lo que sea educar. La educación desde este enfoque no es «sierva» de otras disciplinas o ámbitos extrínsecos sino que se considera valiosa por sí misma porque ayuda al ser humano a desarrollarse como tal. Más aún, la educación es inevitablemente valorativa y querer «negar los valores sería renegar de la condición humana y aniquilar el valor significaría suprimir la posibilidad de la educación misma» (García Aretio, Ruiz Corbella y García Blanco, 2009, 190). Esta reflexión de mayor alcance nos introduce en el «área de la ética».

Siguiendo la célebre clasificación aristotélica (Ética a Nicómaco, 1139b-1141b), podemos decir que la educación se descubre como un ámbito propio de la racionalidad práctica y no de un saber especulativo ni tampoco técnico. Pues se trata de una praxis que se ha de realizar y no de un objeto de contemplación ni de manipulación. No tratamos de objetos de la naturaleza sino de personas que no deben ser instrumentalizadas y cuya praxis constituye —al decir de Ortega - un auténtico "quehacerse», es decir, el fin que se persigue es intrínseco a la actividad y no es otro que desarrollarse plenamente como personas. Esto implica efectivamente habérselas con la libertad, tanto del educando como del educador (Jover, 2002). Pues no somos seres hechos de una vez por todas sino que esencialmente somos «seres en proyecto (pro-yecto)» y la 
«vida humana» se caracteriza precisamente por la futurición (Ortega y Gasset, 2008, VIII, 369-371). Así pues la educación es la concreción y conducción de ese gran proyecto de llegar a desarrollar y "sacar fuera» (educere) todas nuestras capacidades y facultades en vistas a unos ideales, fines o valores personales, sociales y culturales, que nos alimentan, nos guían, nos orientan y, por así decir, tiran de fuera de nosotros hacia sí (educare).

Efectivamente, ya desde Aristóteles la función propia de la racionalidad práctica es la de orientar la acción atendiendo a que «las cosas pueden ser de otra manera» y a que no existe una necesidad de que éstas sean como de hecho son. De este modo se pone de manifiesto lo propicio de regular y orientar a partir de principios que atiendan a las circunstancias concretas de cada educando. Pues no se puede soslayar que el mundo que habita el ser humano está colmado de normas, valores y significados múltiples, y no sólo de hechos carentes de valor (tal y como la ciencia natural busca explicar). Entender y asumir esto, a su vez, implica considerar que el mundo de los valores y, en definitiva, el mundo de la ética no está abocado a la arbitrariedad sino a la racionalidad. La educación sigue siendo un ámbito propicio para el cultivo de la razón en los educandos aun en tiempos de posmodernidad, pero no una racionalidad propensa a la burocratización estrecha de miras y reticente a lo emocional, sino la de un sujeto activo, crítico, creativo y libre (Gozálvez, 2010).

Así pues, vincular la educación con la racionalidad práctica nos lleva a poner de manifiesto que la actividad propiamente práctica no es descriptiva sino principalmente normativa, ya que se trata de regular u orientar la acción con vistas a los fines perseguidos. De este modo cobra todo su sentido hablar de buena o mala educación. No sólo porque desde una racionalidad instrumental de orden mesológico o estratégico solo se consigue dar con los medios más adecuados para unos fines ya dados, sino porque de lo que trata es de plantearse cuáles son los fines más elevados y dignos de ser buscados en la labor educativa de formar plenamente a las personas. Qué duda cabe de que en esta búsqueda habrá de considerarse y evaluarse las diferentes formas culturales e históricas de entender el perfeccionamiento humano. Lo que lleva a un importante esfuerzo de hermenéutica intercultural por desentrañar las claves éticas de la educación para nuestra sociedad actual (Gracia, 2011a).

2. INSUFICIENCIA DE LA INVESTIGACIÓN EMPÍRICA PARA DESENTRAÑAR LOS FINES Y VALORES DE LA EDUCACIÓN

A tenor de lo expuesto anteriormente podemos afirmar que la investigación empírica puede servir para la comprensión de elementos biológicos tales como la mejora del bienestar físico o la educación para la salud (hábitos alimenticios, desarrollo psicomotriz). También puede incidir en aspectos de índole psicológica y sociocultural tales como desarrollo secuencial de habilidades cognitivas y emocionales complejas. Pero la investigación empírica es estéril 
y poco puede aportar en el nivel de la reflexión en torno a los fines y valores que ha de orientar y decir cómo debe ser la educación y no simplemente cómo funciona. La limitación de la investigación empírica a este respecto es flagrante pues este tercer nivel normativo o valorativo, sin embargo, es el que vertebra e impregna las decisiones últimas tanto del nivel físico-biológico como del nivel psicológico-social. Lo que en él está en juego son las variables para determinar en qué consiste el desarrollo humanizador. Y es efectivamente en este nivel en el que la reflexión filosófica contribuye extraordinariamente (Gil y Reyero, 2014).

La cuestión en torno al fin último de la educación es una pregunta radicalmente filosófica. Radical porque va al fundamento del quehacer educativo y filosófica porque sólo se puede plantear desde una reflexión que trasciende los problemas puramente técnicos. Es una pregunta que pone en el punto de mira el modelo de persona que queremos llegar a ser y qué sociedad queremos construir. A juicio de L. García Aretio, M. Ruiz Corbella y M. García Blanco (2009, 193-194) cuatro son los «fundamentos de los fines de la educación»: condicionalidad, antropología, axiología y sociedad. Por nuestra parte, desde un enfoque hermenéutico crítico en clave ética, que más abajo expondremos y que se hace cargo de que toda actividad educadora parte de examinar e interpretar la sociedad a la que se dirige, sin embargo, planteamos si no es necesario y más fundamental incidir no sólo en la «escala de valores aceptada» sino en qué bienes objetivamente forjan un modelo humanizador de persona. Sin restar atención a la relatividad propia de los contextos históricos y culturales que hacen efectivos los diversos modos de autorrealización humana, desde nuestra óptica el fin último de la educación introduce un elemento axiológico y normativo que trasciende el horizonte cultural particular y habilita a las personas hacia el diálogo intercultural (García López, Gozálvez Pérez, Vázquez Verdera y Escámez Sánchez, 2011, 125-136). Incluso, a nuestro modo de ver, el desarrollo de las «capacidades lógico-argumentativas (dominio del lenguaje simbólico, del pensamiento crítico y sus consecuencias...)» sólo es realmente satisfactorio si a su vez se desarrollan las «capacidades morales (autonomía y responsabilidad, sentimientos de reciprocidad e interiorización razonada de valores éticos democráticos)». Sin estas últimas, las primeras derivan en una peligrosa «astucia de la razón» o en una habilidad carente de sabiduría práctica (phrónesis)2. El fin último es un fin marcadamente ético.

A nuestro juicio no son sólo los estudios de antropología filosófica o ciencia política los que consiguen iluminar este nivel fundamental de la educación, aunque obviamente éstos no se pueden dejar de lado (García Amilburu y García Gutiérrez, 2012, 35-46). Más bien, es principalmente la investigación ética la

2 Es clásica la distinción aristotélica entre la mera habilidad (panourgía) y la sabiduría práctica (phrónesis) para incidir en la necesidad de que no sólo los medios sino también y principalmente los fines sean buenos (Ética a Nicómaco, 1142b20-1142b33; 1144a1-1144a35). También Platón en el Gorgias criticó la retórica desprovista de fines éticos como espuria y perversa, pues la elocuencia es más perjudicial que útil si se aparta de la justicia. 
que tiene que ser tenida en cuenta al centrarse precisamente en los valores, las costumbres, las normas, y las ideas acerca de lo bueno y lo malo que dirigen el desarrollo del carácter y la conducta del ser humano. Es la ética como filosofía moral la que en definitiva pone de manifiesto los sentidos últimos de la formación humana (Gil Cantero, 2003). Pues precisamente si de lo que se trata es de desentrañar cuáles han de ser los «fines más altos de la educación» ello no puede desentrañarse si no es a la luz del modelo de sociedad justa que defendamos y desde la ética cobra todo su sentido decir que en un modelo de democracia liberal la educación ha de contribuir a alcanzar la autonomía racional (García Amilburu, 2009, 179-199; Pring, 2003)

A la luz de la ética es posible reflexionar con mayor profundidad y rigor, por ejemplo, acerca del controvertido concepto de «calidad» aplicado a la educación, pues lo que se cuestiona no son los medios para alcanzar determinados objetivos, sino los objetivos mismos del sistema educativo. ¿Es el mercado laboral el fin último de la educación? (Nussbaum, 2010; Gracia, 2018). Podríamos ir incluso más allá, ¿̇se subsume el desarrollo humano en el crecimiento económico (Martínez, 2000) ${ }^{3}$ ? Lo que desde la perspectiva ética se pone de manifiesto es que en la base de las políticas educativas hay determinados estándares más elevados (higher standars) que dirigen y orientan dichas políticas ${ }^{4}$. Por eso ante la reducción de los valores y de la calidad del aprendizaje a una cuantificación del saber a través de determinadas baterías de test, es prioritaria la reflexión acerca de cuáles son estos valores y principios éticos de la educación (Pring, 2014; Mansell, 2007; Phillips, 2006). De hecho la búsqueda de evidencias empíricas sobre los que basar el modelo educativo o asumir que donde no hay resultado de comportamiento medible no hay aprendizajes, es un claro signo del auge de los planteamientos empíricos. Pero, ¿no hay una acuciante inconsistencia al hacer depender la evaluación educativa de estos parámetros de medición aportados por la investigación empírica (Smeyers, 2010)? ¿No ha de ser la evaluación educativa tomada en su sentido más radical algo que conduzca en última instancia a los valores, principios y fines de la educación (Phillips, 2005)?

Con todo ello no queremos negar el valor relativo que ha de tener la investigación empírica y las metodologías de las ciencias experimentales que se lleven a cabo en las diversas ramas de las «ciencias de la educación» (G. Aramburu, 2012, 26-31). Pero la moderna tecnificación del saber y el impacto del llamado «naturalismo» ejercen un extraordinario poder de persuasión en nuestra sociedad y ha acaparado para sí toda «cientificidad» $\mathrm{u}$ «objetividad» del conocimiento. Lo cual — hay que recordar- no es más que una deformación

\footnotetext{
3 Aunque no podemos desarrollarlo aquí esta es a nuestro juicio una de las principales confusiones en las que incurre la LOMCE. (Gracia y Gozálvez, 2016)

4 Caso especialmente llamativo tal y como llama la atención Noelia Fernández (2015) ha sido el impacto que los informes PISA han cobrado en el ideario neoliberal de un mercado sin fronteras ligado a un individualismo consumista y a la retirada del Estado en las áreas de servicios sociales para participar en ella agentes privados.
} 
de lo que el término "ciencia» pueda querer decir (Ortega y Gasset, 2008, VIII, 261; Gadamer, 1990, 9-47; Taylor, 1985, 15-57; Taylor, 1989, 30-107). Frente a este naturalismo un enfoque ético desde la hermenéutica como el de Taylor, Ricoeur o Habermas (cada uno a su modo) contribuye a recuperar el ámbito específico de las ciencias humanas (Geisteswissenschaften) frente a la hegemonía de las ciencias de la naturaleza (Naturwissenschaften) y pone en primer plano la necesidad de una reflexión ética para una fundamentación axiológica de la práctica de la educación (García Aretio, 2009, 251). Pues se trata de considerar al ser humano en todas sus dimensiones (especialmente en la propiamente humana referida a fines, valores y normas) en tanto que un auténtico agente (activo) y a nuestro juicio esto es clave en la educación, más aún, este es el enclave ético-hermenéutico de la educación.

3. La METOdOlOGÍA HERMENÉUtico-CRÍTICA Y SU IDONEIDAD PARA ENFOCAR LOS FINES ÉTICOS DE LA EDUCACIÓN

La hermenéutica resulta una metodología especialmente fecunda para el propósito de enfocar adecuadamente el fenómeno educativo (Gallagher, 1992; García Amilburu, 2002). Y lo es precisamente porque atiende a los diferentes elementos históricos y socioculturales que configuran la forma de pensar y de vivir de las personas (Gadamer, 1990, 270-386), que forman parte de la "práctica educativa» y de todo proceso de aprendizaje (García Amilburu y García Gutierrez, 2012). No se trata, por lo tanto, de construir explicaciones anulando la dimensión axiológica o normativa que constituyen a las sociedades humanas, sino de hacerse cargo de ellas y considerarlas como elementos vectores en la formación de las personas (Pring, 2000, 16-27). Sólo teniendo en cuenta los fines éticos en torno a la felicidad o a la justicia que las sociedades y las personas dentro de éstas han tenido es posible entender (verstehen) el fenómeno de la educación adecuadamente en toda su amplitud, caracterizándolo como un proceso de aprendizaje.

El enfoque ético hermenéutico que aquí proponemos supera el sesgo textualista que ha dominado tradicionalmente en la hermenéutica (Grondin, 1999, 41-136; Ferraris, 2000, 12-167; Gallagher, 1992, 319-331) y vincula de un modo extraordinariamente fecundo la metodología hermenéutica con las ciencias humanas (Taylor, 1985, 15-57; Ricoeur, 2000; Gracia, 2011b). Esta hermenéutica aplicada a la educación no es algo forzado que venga desde fuera sino que surge como consecuencia de entender la interpretación más allá del paradigma predominante textual de la lectura y ampliarla en los términos de un proceso de aprendizaje donde tiene lugar una participación vital de personas y donde ya no es el texto sino la acción entendida desde su circunstancia histórica, social, cultural y personal lo que ha de ser "comprendido-interpretadoaplicado» (Gadamer, 1990, 312-317; García Amilburu, 2002, 161-162).

La hermenéutica filosófica constituye una vuelta a la radicalidad de la vida humana en la que «el mundo de la vida» (Husserl), «la existencia» (Heidegger) o 
la «experiencia» (Gadamer) constituyen el elemento prioritario a tener en cuenta (Gadamer, 1990, 246-269 y 352-367; Grondin 1999, 137-178). Bajo esta égida la educación es caracterizada como un proceso genuinamente humano en el que las vivencias y el sentido de la existencia cobran una relevancia extraordinaria. Se trata por lo tanto de partir de la comprensión de la circunstancia particular de cada uno de los sujetos, teniendo en cuenta el sentido y valoraciones que éstos llevan a cabo. Desde esta óptica difícilmente podrá entenderse la experiencia educativa si no es en el contexto social, histórico y cultural que envuelve la vida de los educadores y educandos. Este es por lo tanto el punto de partida de la hermenéutica, a saber, comprender, interpretar y aplicar las prácticas educativas en función de los fines que la educación comporta para los propios agentes del proceso. Y esto encuentra su enclave en las ciencias humanas en general (Taylor, 1985) y más en particular en la educación (Gallagher, 1992; García Amilburu, 2002).

Una «hermenéutica moderada» como la que propone García Amilburu (2002, 152-161) es efectivamente fecunda para la educación porque a) toma los pre-juicios y la tradición histórico-cultural como punto de partida, b) es capaz de trascenderse y alcanzar nuevos horizontes, c) entiende la experiencia educativa lingüísticamente en términos radicalmente dinámicos y dia-lógicos, d) el aprendizaje no se entiende como una aplicación instrumental o mecánica sino en los términos de una apropiación que conduce al autoconocimiento y a pensar por sí mismo, e) la racionalidad que guía el proceso de aprendizaje es fundamentalmente práctica (phrónesis) y más que transmitir conocimientos o habilidades busca formar en la virtud.

En esta aguda caracterización de «hermenéutica moderada» destacaríamos nosotros con más énfasis la dimensión crítica, pero no en los términos de una «crítica de las ideologías» de acuerdo con el debate inicial entre Gadamer y Habermas (Gallagher, 1992, 239-246), disociada de la «experiencia» o la facticidad, sino precisamente emergente desde la propia experiencia humana (Conill, 2006); una experiencia que sin duda es radicalmente educativa. Porque es desde este enclave experiencial y crítico desde el que la educación descubre su entraña ética en toda su potencialidad.

Existe por lo tanto un segundo elemento que no puede ser soslayado a riesgo de derivar en un relativismo impracticable, improductivo e incorregible, a saber, la crítica. Y es este aspecto el que nosotros queremos aquí destacar. Porque los contextos culturales u horizontes de sentido son puntos de partida pero no han de ser tomados de modo clausurado como puntos de llegada.

Estoy hablando de un tipo de naturalismo que haría de la relatividadcultura una fatalidad; un límite en principio. Precisamente porque concibe enteramente la «objetividad» de nuestras valoraciones en función de su imbricación en nuestras diferentes formas de vida, en principio, no permite adoptar un punto de vista desde el cual los bienes consagrados en un modo de vida dado, pudieran parecer perversos o inadecuados (Taylor, 1989, 67) 
La dimensión crítica ha de llevar a cabo una importante labor de exploración y análisis. Dicho de otro modo, lo que las gentes de una sociedad determinada creen que es lo bueno no tiene por qué ser real o éticamente «lo bueno». A la luz de la hermenéutica crítica es por lo tanto necesario examinar si aquellas nociones normativas de determinadas sociedades realmente responden a las exigencias éticas. A este respecto la distinción entre un primer nivel de la experiencia cotidiana, el de la «moral» y un segundo nivel de la reflexión, el de la «ética», puede ser de gran ayuda (Cortina, 1986). Y es en la entraña misma de la educación que encontramos ligada a esta dimensión crítica el célebre concepto de «emancipación» ${ }^{5}$. Pues se trata de que los alumnos maduren, se formen e incluso transformen las situaciones de injusticia establecidas a partir del ejercicio dialógico de la racionalidad práctica ínsita en el mundo de la vida. Desde el enfoque hermenéutico se pone de manifiesto que «el aprendizaje se efectúa a partir de unos conocimientos previos; pero aprender algo no significa quedarse encerrado en la tradición: ésta se transciende cuando se produce el auténtico aprendizaje» (García Amilburu y García Gutierrez, 2012, 106).

Con todo, queremos incidir en que desde el enfoque hermenéutico crítico que defendemos la comprensión y la crítica no constituyen dos elementos separados, sino que todo entender (en-tender) comporta ya un (pre-tender), pues sin considerar los elementos valorativos y el sentido o los sentidos posibles (orientativos en tanto que significativos y por lo tanto regulativos), las prácticas de los propios agentes educadores y educandos serían ininteligibles (Gracia, 2018). De lo que se trata es de destacar este carácter normativo que la propia actividad educativa comporta e intentar examinar si hay pretensiones que pueden valer comúnmente e incluso de forma generalizable. Así, el entender (Verstehen) puede llegar a convertirse en un entendimiento o acuerdo mutuo (Verständigung) acerca de los fines éticos de la educación. A nuestro juicio, la hermenéutica crítica en el nivel trascendental de la reflexión ética consigue dar con determinados elementos que han de valer de modo universal (Apel, 1985a, 33-49; Apel 1985b, 394-413). A este respecto el caso paradigmático lo constituye el trato respetuoso a toda persona humana. Es desde esta reflexión trascendental de calado ético que damos, por ejemplo, con el hallazgo conceptual de la «dignidad humana» (Kant, 1992). Lo cual constituye también un valioso hallazgo para los fines de la educación, pues considerar a las personas como fines y nunca como medios implica que éstas no pueden instrumentalizarse para objetivos particulares o ideológicos. Una educación que considera al educando como un ser humano con dignidad, que

5 No es el momento de detenerse en el enjundioso concepto de «emancipación» estrechamente vinculado con la teoría crítica (Cortina, 2008; Gallagher, 1992, 239-275). Quizá sí sea interesante destacar que el «interés emancipatorio» entendido como «utopía» y originalmente separado de las ciencias hermenéuticas por la crítica de las ideologías (Habermas, 1971), sin embargo, acabará incluyéndose en la dimensión ética de la «ética del discurso» en los términos de una mayor consideración de la experiencia vital, abonando el terreno para un acercamiento de la hermenéutica y la ética (Grondin, 1999, 185-199; Conill, 2006, 195-201). 
no es susceptible de ser instrumentalizado, permite trazar una separación clave entre educar y adoctrinar o entre la formación humana y la mera instrucción. La formación del ser humano (Bildung y no Ausbildung) ${ }^{6}$ a la luz del enfoque de la ética hermenéutica constituye el fin último innegociable que justifica la educación.

Incidir en este aspecto ético de la hermenéutica comporta, a nuestro juico, importantes ventajas para adquirir un adecuado enfoque de la experiencia educativa. A continuación vamos a destacar once de esas claves que nos ofrece el enfoque de la ética hermenéutica aplicado a la educación.

\section{Claves desde el enfoque ético-hermenéutico para la educación}

La primera de las claves que ofrece el enfoque de la ética hermenéutica para la educación es la de descubrir al ser humano en toda su dignidad, es decir, como valor absoluto. Lo cual implica tomarse muy en serio el respeto a su singularidad como persona y el reconocimiento de determinados derechos que le son inherentes. Adoctrinarle, instrumentalizarle, manipularle o ideologizarle son formas de vulnerar su dignidad y en la medida que cosifica a las personas constituye un atentado contra el fin ético de la educación como formación de seres humanos.

En segundo lugar, la ética hermenéutica constituye un enfoque adecuado para evitar el adoctrinamiento. Pues efectivamente la educación bajo la óptica de la ética hermenéutica no consiste únicamente en alcanzar creencias verdaderas sino también en el modo como dichas creencias o conocimientos se adquieren. Y para ello es necesario salvaguardar tanto, por una parte, el valor epistémico de la comprensión como, por otra, el valor moral de la autonomía (Callan y Arena, 2009, 116-119). A nuestro juicio, es la ética hermenéutica en su doble virtualidad (hermenéutica y ética) la que permite fomentar en el educando la amplitud de miras y de horizontes (open-mindedness) descubriendo la parte de verdad que pueda haber en otras formas de vida y de pensar (Hare, 1985). Desde este enfoque la educación no puede ser un mero instrumento sino el cultivo de los valores que permiten un ejercicio crítico, comprensivo y autónomo de la racionalidad.

\footnotetext{
6 No podemos abundar en el potencial ético-hermenéutico-crítico del concepto de formación. Como una primera aproximación podemos acudir a la «red nomológica de la educación» tal y como la planteó José Manuel Esteve (2010, 28-54). Para profundizar más ayuda recordar la clásica distinción en la tradición germana entre Bildung (formación humana) y Ausbildung (especialización profesional) para subrayar cuál es el fin último innegociable que justifica la educación. Véase el prolijo estudio de Vierhaus, (1972) donde desentraña la Bildung como «concepto pedagógico» vinculándolo al de Erziehung (educación) al menos desde 1770 en plena Ilustración. Todo lo cual nos llevaría a profundizar en autores como Herder, Goethe o Humboldt (Vierhaus, 1972, 512-521). También Gadamer dedica sendos análisis al concepto de Bildung en el marco de la tradición humanista en Verdad y método (Gadamer, 1990:15-24).
} 
En tercer lugar, la acción educativa a la luz de la ética hermenéutica no puede ser entendida como una "acción instrumental» sino en el enclave de una «acción comunicativa» (Habermas, 1987, 143-146; Cortina, 2008, 118-124). La formación de profesionales y técnicos competentes ha de estar precedida y siempre acompañada con la forja de unos valores y de un carácter ético. Es a esto a lo que Gadamer recogiendo una dilatada tradición humanista llama Bildung («formación general», frente a Ausbildung), (Gadamer, 2000, 37; Gadamer, 1990, 15-24). Por una parte las enseñanzas técnicas guiadas por una racionalidad lógico-instrumental corren el riesgo de terminar por vaciar la vida de las personas, ya que la técnica por sí sola es incapaz de determinar el contenido de la vida (Ortega y Gasset, 2005, IV: 539; Bilbao, Fuertes y Guibert, 2006). Por otra parte, ser un buen profesional implica cumplir una serie de exigencias éticas (Hortal, 2002). Pues para ser un profesional completo, un buen profesional, un profesional excelente, no basta con ser técnicamente capaz, y esto es más manifiesto en los profesores donde «los aspectos éticos de la labor docente forman parte de la entraña misma de su trabajo cotidiano» (Martínez, 2010, 14).

En cuarto lugar, Esta formación general en la que ha de consistir toda educación tiene lugar a través de la conversación en la que el protagonismo recae sobre el educando (Gadamer, 2000). El valor del reflexivo «educar-se» es precisamente incidir en que no se trata tanto de pretender enseñar como de estar dispuesto a aprender. Lo cual no quiere decir que la figura del maestro sea irrelevante, pero sí ha de partir del presupuesto de que la clave está en suscitar un cuestionamiento previo en el alumno. La conversación acontece porque la pregunta prevalece en valor y sentido y de aquí la importancia para la hermenéutica de plantear adecuadamente las preguntas; de mantener críticamente (autocríticamente) los interrogantes para poder reapropiarse uno de sí y "acceder él mismo a su morada» (einhausen) (Gadamer, 2000; Taylor, 1994). A la luz de la hermenéutica (auto-)crítica toda (auténtica) educación es un educar-se porque todo docente es a su vez un discente, y el saber se mueve de manera latente como precomprensión en la conversación, lo cual no elimina sino que retroalimenta el nivel intrasubjetivo del diálogo interior con uno mismo.

En quinto lugar, el enfoque de la ética hermenéutica no separa la dimensión crítica de la experiencia sino que descubre la crítica desde la propia experiencia vital. Pues recoge la doble virtualidad crítica: las aportaciones críticas de la razón en la experiencia, pero también, tras el giro hermenéutico experiencial, de la experiencia en la razón (Conill, 2006). El aprendizaje es significativo cuando incide en la circunstancia vital de los propios educandos. El enfoque de la ética hermenéutica parte de esta significación para conectarla con la significatividad de la vida en su conjunto. La educación así enfocada vincula la experiencia vital con los fines éticos de la humanidad, pues la significación de la vida ha de ser renovada por el potencial reflexivo que la experiencia educativa implica.

En sexto lugar, la educación a la luz de la ética hermenéutica está comprometida con el contexto cultural, histórico, social y personal de educandos 
y educadores y descubre en este compromiso todo su potencial prácticotransformador. Y lo está porque el ejercicio de la reflexión o la «meditación» está vinculada a la historia y a la propia cultura y de poco sirve la educación si ésta no va orientada a «salvar la propia circunstancia» (Ortega y Gasset, 2012, 41-89).

En séptimo lugar, la ética hermenéutica que aquí proponemos como guía de la educación previene de posibles autoritarismos y evita la perpetuación de posibles prejuicios perjudiciales, el «prejuicio de perfección» (Habermas, 1987, 186-192). En este sentido el reconocimiento de la autoridad no debe impedir el ejercicio de la racionalidad y la capacidad para cuestionar las normas establecidas. Pero este cuestionamiento no es visto como una furia destructiva contra toda organización educativa necesaria sino como una forma de ejercer la crítica y autocrítica constructiva.

En octavo lugar, recuperando el legado aristotélico de la «sabiduría práctica» (phrónesis), la ética hermenéutica radica la sabiduría práctica en la experiencia, pero va más allá del planteamiento aristotélico al reconocer la necesidad del momento universal kantiano de la norma. No basta sin embargo, con una posición universalista de la ley, sino que a la luz de la hermenéutica hay que atender a los conflictos que surgen de la exigencia de aplicar la norma universal (Ricoeur, 1996, 258-327). A nuestro modo de ver esto tiene también una extraordinaria significación para la educación, porque de lo que se trata no es tanto de aplicar ciegamente normas sino de comprender los contextos, sus posibilidades y sobre todo a los sujetos implicados, cada uno en su singularidad. Ser capaz de reconocer este pluralismo en el respeto a las personas es encarnar la sabiduría práctica hermenéutica. Pues atender a la diversidad presupone la capacidad para aplicar normas a las situaciones singulares de las personas. Mientras que la ley por la ley fácilmente acaba cayendo en el rigorismo, la sabiduría práctica implica prestar atención a la alteridad concreta de cada persona, hasta el punto de que la excepción se convierta en un rostro.

En noveno lugar, el enfoque ético-hermenéutico dota a la educación de la facultad fundamental de la "cordura» al articular conocimiento, prudencia, justicia y gratuidad (Cortina, 2007, 247-262). Pues frente a la frialdad del racionalismo y a la ceguera del emotivismo, la ética hermenéutica considera que la inteligencia humana es sentiente, emocional y afectiva y que una adecuada educación sentimental es la mejor promesa del éxito (Gozálvez, 2000). Y recuerda que es urgente recuperar la educación del deseo y la capacidad para degustar los valores, pues no basta sólo con la enseñanza de las habilidades técnicas, es necesaria la educación de las habilidades sociales. Es esta una educación que conecta de manera fecunda razón y corazón; justicia y gratuidad. Una educación que recuerda que el fundamento de la labor educativa no ha de estar en un cálculo de costes y beneficios sino en descubrir aquello que nos realiza humanamente.

En décimo lugar, la ética hermenéutica es también el prisma adecuado para la educación de una ciudadanía auténtica. Y lo es porque desde ella es posible articular perspicazmente lo más granado de la tradición liberal, republicana y 
comunitarista de lo que ha dado en llamarse «mínimos de justicia»y «máximos de vida feliz» (Cortina, 1997, 21-38). La ética hermenéutica recuerda que ambos no deben separarse, pues si bien es cierto que los máximos se purifican desde los mínimos, también lo es que los mínimos se alimentan sustantivamente desde los máximos (Taylor, 1986; Ricoeur, 1990; Cortina, 2001, 142-144). Esta educación para la ciudadanía auténtica entiende que la autenticidad es clave en la formación humana (Taylor, 1994). Porque, de un lado, un cosmopolitismo desarraigado acaba derivando en hipocresía moral (Nussbaum, 1996), pero también, en el extremo opuesto, porque un nacionalismo encapsulado acaba asfixiando al individuo y diluyéndolo en la colectividad. Frente a éstos nuestra ética hermenéutica propone una educación para la ciudadanía global en clave intercultural (Gracia, 2013; Gracia, 2018)

En undécimo lugar, la ética hermenéutica es especialmente pertinente para enfocar adecuadamente la propuesta de una educación intercultural. Y lo es porque su foco de atención es partir de los contextos y horizontes culturales de cada uno de los miembros de la comunidad educativa, para redescubrirlos a la luz de un diálogo que busca la «fusión de horizontes» (Gadamer, 1990, 305312; Taylor, 2002). Hay que aclarar que la interculturalidad no es equivalente a la multiculturalidad (Taylor, 2012; Conill, 2002; Santos Rego, 2013). Nuestro modo de enfocar esto es que igual que hay diferencias que deben ser reconocidas hay desigualdades que han de ser erradicadas. La educación intercultural ha de moverse entre el reconocimiento de la igual dignidad de todos los alumnos y el fomento de las enriquecedoras diferencias singulares de cada uno, que contribuyen a un desarrollo personal humanizador.

\section{CONCLUSIÓN}

La ética hermenéutica que aquí hemos expuesto se presenta como un valioso enfoque desde el que alumbrar el fenómeno de la educación y, más en concreto, los fines que dan sentido y justifican la práctica educativa. Efectivamente, adoptar este enfoque contribuye muy positivamente no solo a comprender la naturaleza de algunos fenómenos que tienen lugar en el seno del proceso educativo, sino también a regular y reparar en el carácter normativo que justifica dicha práctica. Pues el término educación tomado en su radicalidad ya contiene el carácter normativo y regulativo de buena o mala educación. Por eso decir "persona educada» ya quiere decir bien educada (frente a maleducada). Desde esta dimensión ético-hermenéutica no basta con entender la formación en base a unas tradiciones heredadas sino que la reflexión, el análisis y la crítica constituyen elementos indispensables para comprender adecuadamente qué quiera decir (buena) educación. Si bien es cierto que no podemos negar la referencia insustituible del contexto social, histórico y cultural, tampoco deja de serlo que en el centro de la educación siempre hay personas que por el hecho de serlo tienen un valor intrínseco más allá de culturas o tradiciones 
particulares. El valor de la educación es por lo tanto relativo a éstas y no a aquéllas

\section{BibliografíA}

Apel, K.-O. (1985a). Transformación de la filosofía I. Análisis del lenguaje, semiótica y hermenéutica. Madrid: Taurus.

Apel, K.-O. (1985b). Transformación de la filosofía II. El a priori de la comunidad de comunicación. Madrid: Taurus.

Bilbao, G., Fuertes, J., Guibert, J. M. (2007). Ética para ingenieros. Bilbao: Desclée de Brower.

Callan, E. y Arena, D. (2009). «Indoctrination», en: Siegel, H. (ed.), The Oxford Handbook of Philosophy of Education. Oxford: Oxford University Press, pp. 104-121.

Conill, J. (2006). Ética hermenéutica. Crítica desde la facticidad. Madrid: Tecnos.

Conill, J. (2002). Glosario para una sociedad intercultural. Valencia: Bancaja.

Cortina, A. (1986). Ética mínima. Madrid: Tecnos.

Cortina, A. (1997). Ciudadanos del mundo. Hacia una teoría de la ciudadanía. Madrid: Alianza Editorial.

Cortina, A. (2001). Alianza y contrato. Política, ética y religión. Madrid: Trotta.

Cortina, A. (2007). Ética de la razón cordial. Educar en la ciudadanía en el siglo XXI. Oviedo: Nobel.

Cortina, A. (2008). La escuela de Fráncfort. Crítica y utopía. Madrid: Síntesis.

Esteve, J. M. (2010). Educar: un compromiso con la memoria. Un libro para educar en la libertad. Barcelona: Octaedro.

Fernández, N. (2015). «Pisa como instrumento de legitimación de las reformas sociales», en: Bordon. Revista de Pedagogía. Vol. 67, nº 1, pp. 165-178.

Ferraris, M. (2000). Historia de la hermenéutica. Madrid: Akal.

Gadamer, H.-G. (1990). Hermeneutik I. Wahrheit und Methode. Grundzüge einer philosophischen Hermeneutik. Gesammelte Werke I (Tübingen, Mohr Siebeck).

Gadamer, H.-G. (2000). La educación es educarse. Barcelona: Paidós.

Gallagher, S. (1992). Hermeneutics and Education. New York: State University of New York Press.

García Amilburu, M. (2002). La educación, actividad interpretativa: Hermenéutica y filosofía de la educación. Madrid: Dykinson.

García Amilburu, M. (2009). Aprendiendo a ser humanos. Una antropología de la educación. Barñáin: Eunsa.

García Amilburu, M. y García Gutiérrez, J. (2012). Filosofía de la educación. Cuestiones de hoy y de siempre. Madrid: Narcea.

García Aretio, L., Ruiz Corbella, M. y García Blanco, M., (2009). Claves para la educación. Actores, agentes y escenarios en la sociedad actual. Madrid: Narcea.

García López, R., Gozálvez Pérez, V., Vázquez Verdera, V., Escámez Sánchez, J. (2011). Repensando la educación: cuestiones y debates para el siglo XXI. Valencia: Brief.

Gil Cantero, F. (2003). La Filosofía de la educación como teoría ética de la formación humana, Revista Española de Pedagogía, 224:61, pp. 115-130.

Gozálvez, V. (2000). Inteligencia moral. Bilbao: Desclée de Brower.

Gozálvez, V. (2010). Hacia una reconstrucción de la razón pedagógica. Teoría de la educación, Revista interuniversitaria, 22:2, pp. 19-42.

Gozálvez, V., Traver, J. A., García, R. (2011). El aprendizaje cooperativo desde una 
perspectiva ética. Estudios sobre Educación 21, pp. 181-197.

Gracia, J. (2011a). Ética y política en Charles Taylor. Claves para una sociedad intercultural. Saarbrücken: Editorial Académcia Española.

Gracia, J. (2011b). Antropología filosófica en Charles Taylor. Perfil hermenéutico del ser humano. Saarbrücken: Editorial Académica Española.

Gracia, J. (2013). «Educación para la ciudadanía global en clave intercultural», en: Diálogo Filosófico, no 64, pp. 77-94.

Gracia, J. (2018). El desafío ético de la educación. (Madrid, Dykinson).

Gracia, J. y Gozálvez, V. (2016). «Justificación filosófica de la educación en valores éticos y cívicos en la educación formal. Análisis crítico de la LOMCE», en: Teoría de la Educación, no 28, pp. 83-103.

Grondin, J. (1999). Introducción a la hermenéutica filosófica. Barcelona: Herder.

Habermas, J. (1971). «Zur Gadamers Wahrheit und Methode», en: Apel, K-O. (ed.) Hermeneutik und Ideologiekritik. Francfor: M, Suhrkamp)

Habermas, J. (1987). Teoría de la acción comunicativa I. Racionalidad de la acción y racionalización social. Madrid: Taurus.

Hare, W. (1985). In Defence of Open-mindedness. Montreal: McGill-Queen's University Press.

Hortal, A. (2002). Ética general de las profesiones. Bilbao: Desclée de Brower.

Jover, G. (2002). «La filosofía de la educación en España: Revisión y perspectivas de futuro», en: VV.AA. Educación, Ética y ciudadanía. Madrid: Uned, pp. 369-384.

Kant, I. (1992). Fundamentación de la metafísica de las costumbres. Madrid: Real Sociedad Matritense de Amigos del País.

Mansell, W. (2007). Education by numbers: The Tyranny of Testing. London: Politico's Publishing.

Martínez, E. (2000). Ética para el desarrollo de los pueblos. Madrid: Trotta.

Martínez, E. (2010). Ética profesional de los profesores. Bilbao: Desclée De Brouwer.

Nussbaum, M. (1996). «Patriotism and Cosmpolitanism», en: Nussbaum, M. y Cohen, J. (eds.), For Love of Country. Debating the limits of patriotism. Boston: Beacon Press, pp. 3-17

Nussbaum, M. (2010). Not for profit. Why democracy needs the humanities. New Jersey: Princeton.

Ortega y Gasset, J. (2012). Meditaciones del Quijote. Madrid: Cátedra. Edición con prólogo y notas de Julián Marías.

Ortega y Gasset, J. (2008). ¿Qué es filosofía?, en: Obras completas. Vol. VIII. Madrid: Fundación Ortega y Gasset/ Taurus, pp. 235-275.

Ortega y Gasset, J. (2005). "Misión de la universidad», en Obras completas. Vol. IV. Madrid: Fundación Ortega y Gasset/ Taurus, pp. 531-568.

Phillips, D. C. (2005). «The contested mature of empirical educational research (and why philsophy of education offers little help)», en: Journal of Philosophy of Education, 39:4, pp. 577-597.

Phillips, D.C. (2006). A guide for the perplexed: Scientific educational research, methodoltry, and the gold versus platinum standards, Educational Research Review, 1:1, pp. 15-26.

Pring, R. (2000). Philosophy of Educational Research. London: Continuum.

Pring, R. (2003). «La polémica sobre los fines de la educación», en: García Amilburu (ed.), Claves de la Filosofía de la educación. Madrid, Dykinson.

Pring, R. (2014). «From Disguised Nonsense to Patent Nonsense: Thinking Philosophically», en: Revista española de pedagogía, 258: 72, mayo-agosto, pp. 249-261. 
Ricoeur, P. (1990). «Éthique et morale», en: Revista portuguesa de Filosofía XLVI, pp. $5-17$.

Ricoeur, P. (1996). Sí mismo como otro. Madrid: Siglo veintiuno).

Ricoeur, P. (2000). Del texto a la acción. Ensayos de hermenéutica II. Buenos Aires: FCE.

Santos Rego, M. A. (2013). Cosmopolitismo y educación. Aprender y trabajar en un mundo sin fronteras. Valencia: Brief.

Smeyers, P. (2010). "Statistic and inference to the best explanation: living without complexity», en: Smeyers, P. y Depaepe, M. (eds.), Educational research: the ethics and aesthetics of statistic. New York: Springer, pp. 161-176.

Taylor, C. (1985). Philosophy and the human science. Philosophical papers II. Cambridge: Cambridge University Press.

Taylor, C. (1986). «Die Motive einer Verfahrensethik», en; Kuhlman, W., Moralität und Sittlichkeit: Das Problem Hegels und die Diskursethik. Frankfurt: Suhrkamp.

Taylor, C. (1989). Sources of the Self. The Making of the Modern Identity. Cambridge: Cambridge University Press.

Taylor, C. (1994). Ética de la autenticidad. Barcelona: Paidós.

Taylor, C. (2002). «Understanding the Other: A Gadamerian View on Conceptual Schemes», en: Malpas, J., Gadamer's Century: Essays in Honor of Hans-Georg Gadamer. Boston: MIT Press.

Taylor, C. (2012). "Interculturalism or Multiculturalism», en: Philosophy \& Social Criticism 38, no. 4-5, pp. 413-423.

Vierhaus, R. (1974). «Bildung», en: Brunner, O., Conze, W. y Koselleck, R. Geschichtliche Grundbegriffe: Historisches Lexikon zur politisch-sozialen Sprache in Deutschland. Band. 1, Klett-Cotta, Stuttgart, pp. 508-551.

Universitat de València; IES Massamagrell

Javier.Gracia@uv.es

Isbel.tamarit@uv.es

JaVier Gracia Caladín

ISABEL TAMARIT

[Artículo aprobado para publicación en enero de 2018] 